\title{
A rare cause of hematuria and abdominal pain: our clinical experiences with Nutcracker Syndrome
}

\author{
Mehmet Tort, Ümit Arslan, Ziya Yıldız, Eyüp Serhat Çalık, Mehmet Ali Kaygın \\ Received: January 11, 2014 Accepted: January 15, 2014 Published online: February 10, 2015
}

Compression of the left renal vein between the abdominal aorta and the superior mesenteric artery is named as Nutcracker syndrome (NCS). It is an extremely rare pathology which usually manifests with hematuria, pain, or proteinuria. The diagnosis of the disease is primarily based on clinical suspicion. Various treatment models such as observation, conservative therapies, and surgery are available. In this article, we discuss a rare condition of NCS in three patients with left renal vein compression in the light of radiological findings.

Keywords: Abdominal pain; compression of the left renal vein; hematuria; Nutcracker syndrome.

Nutcracker syndrome (NCS) or renal entrapment syndrome was firstly reported by El-Sadr and Mina ${ }^{[1]}$ in 1950; however, the first definition was made by Schepper in 1972, who described the disease as compression of the left renal vein between the aorta and the superior mesenteric artery. ${ }^{[2]}$ Nutcracker syndrome is characterized by an external compression of the outflow from the left renal vein into the inferior vena cava. Nutcracker phenomenon (NCP) is typically described as the compression of the left renal vein between the aorta and the superior mesenteric artery, restriction in left renal vein due to external compression, and dilation of the segment proximal to the stenotic renal vein due to an increased pressure. By some authors, this definition of NCP is called as anterior-type NCP. As in posterior NCS, it is defined as the external compression of the retroaortic renal vein by vertebral column. ${ }^{[3]}$ Wilkie syndrome which is characterized by compression of third part of duodenum (in a similar way with anterior NCS) can be simultaneously seen with anterior NCS. ${ }^{[4]}$

\section{CASE REPORT}

Case 1-A 22-year-old male patient was admitted to the emergency department of our hospital with abdominal pain. On physical examination, the patient had remarkable pain attacks radiating to the right inguinal region. Blood and urinalysis revealed no pathology except microscopic hematuria. Ultrasonography (USG) which was performed to exclude acute abdomen showed a dilated left renal vein. These findings suspected us NCS. Abdominal computed tomography
(CT) demonstrated a large caliber left renal vein compressed between the abdominal aorta and superior mesenteric artery. The patient was hospitalized with the initial diagnosis of NCS (Figure 1). Medical work-ups were done preoperatively. Comorbid familial Mediterranean fever was diagnosed. Surgery was performed with a median abdominal incision. The superior mesenteric artery and the renal vein were mobilized (Figure 2). Saphenous vein bypass graft was placed between vena cava inferior and left renal vein at the anterior aorta level. The patient was then taken to the postoperative intensive care unit. The patient was given oral nutrition on the second postoperative day. In a stable condition, the patient was transferred to the hospital service on the third postoperative day. No complications were observed during follow-up visits and he was discharged from the hospital with full recovery on the seventh postoperative day.

Case 2- A 28-year-old woman was admitted to the internal medicine department of our hospital with recurrent hematuria attacks and abdominal pain. Using CT, the patient was diagnosed with NCS and was hospitalized in our service. Urinalysis detected 2+ blood. Preoperative procedures were completed and the patient underwent surgery. The left renal vein was fully incised and mobilized

Department of Cardiovascular Surgery, Erzurum Regional Training and Research Hospital, Erzurum, Turkey

Corresponding author: Mehmet Tort, M.D. Erzurum Bölge Eğitim ve Araştırma Hastanesi, Kalp ve Damar Cerrahisi Kliniği, 25240 Erzurum, Turkey.

Tel: +90 442 - 3165763 e-mail: dr_tort@hotmail.com 


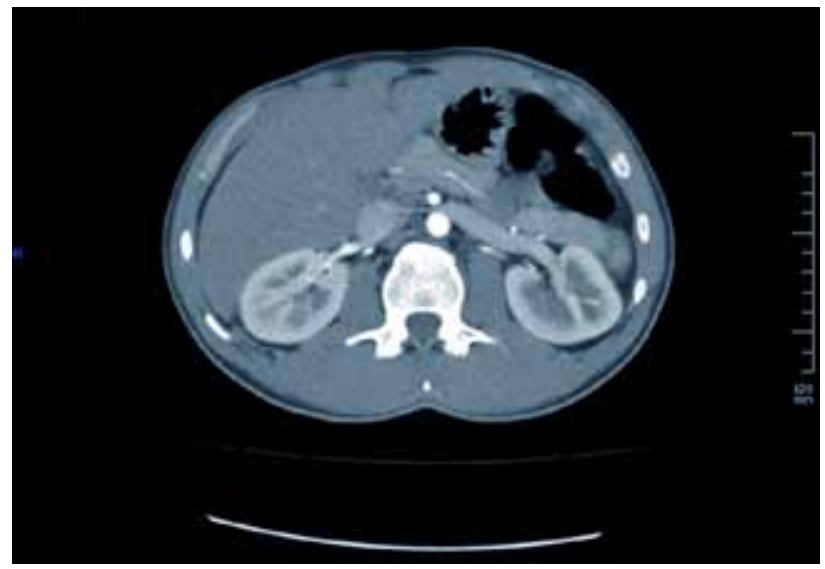

Figure 1. Computed tomography angiographic view of the patient with Nutcracker syndrome.

through the superior mesenteric artery and the aorta. End-to-end anastomosis was unable to be done due to far distance, and therefor a vascular hemostasis was able to be obtained by the insertion of saphenous vein interposition graft $(2 \mathrm{~cm})$. The patient was stabilized and transferred to the hospital service on the second postoperative day. The patient was discharged from the hospital with full recovery on the sixth postoperative day.

Case 3- A six-year-old female patient who received medical treatment and was under follow-up in the pediatric service due to recurrent urinary infections was diagnosed with NCS by abdominal USG. The patient was consulted to our clinic. Blood and urinalysis revealed no significant pathology. Abdominal CT angiography revealed the compression of the left renal vein between the aorta and superior mesenteric artery. Compression was not severe and a dilatation was not detected in the left renal vein. The patient was diagnosed with NCP and a medical follow-up was scheduled for the patient. The patient did not present with hematuria and a remarkable sign of compression was not observed during two-year follow-up. The follow-ups were sustained.

\section{DISCUSSION}

The NCP refers to the compression of the left renal vein between the aorta and the superior mesenteric artery. ${ }^{[5]}$ Nutcracker syndrome refers to the NCP together with complicated symptoms. ${ }^{[5]}$ As there are a limited number of experiential case reports and case series on NCS, the definite incidence of the syndrome remains unknown.

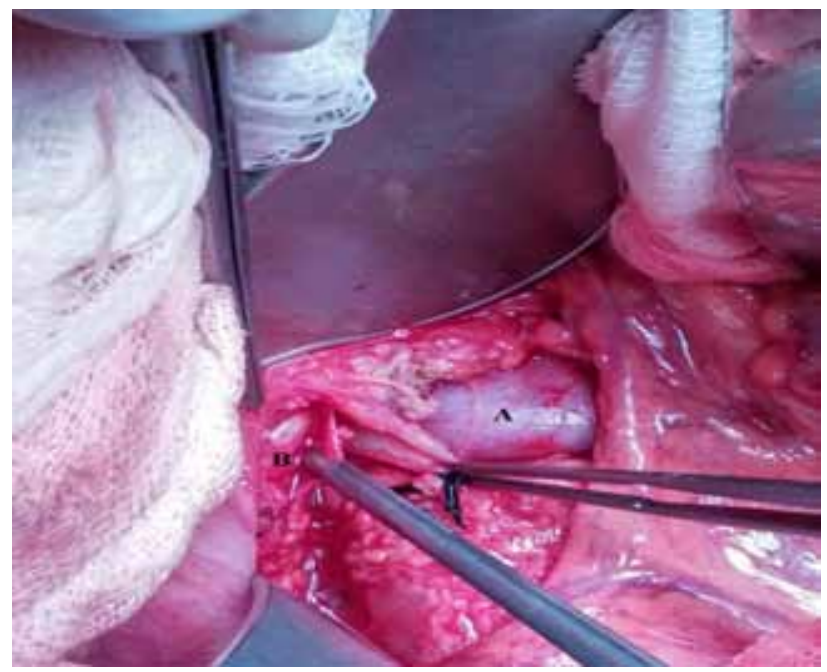

Figure 2. Perioperative view of the patient. A: Left renal vein B: Superior mesenteric artery.

Since NCS is a rare disease, the diagnosis is often delayed due to its non-specific diagnostic criteria. Most patients, children, in particular, are asymptomatic. ${ }^{[5]}$ This pathology is more commonly seen in young women. The disease can be clinically silent or can give symptoms such as hematuria in $66 \%$ of the patients, pelvic pain, flank pain, varicocele, dysmenorrhea, and dysuria. ${ }^{[6]}$ Hematuria which is the most commonly seen symptom is attributed to the rupture of thin-walled varices at the level of renal calyces due to elevated venous pressures. Orthostatic proteinuria which is defined as protein leakage from calyceal system due to an elevated venous pressure is seen in \%0.6-10.7 of the Nutcracker cases and it is a less common laboratory finding, compared to hematuria. ${ }^{[7]}$

Color Doppler USG is an initially preferred noninvasive method with a rough $\% 78$ sensitivity and \%100 specificity. Contrast CT, magnetic resonance imaging, inferior vena cava manometry are used in the first step to establish the final diagnosis, retrograde flebografia, an invasive screening method, follows these methods. Renocaval pressure gradient less than $1 \mathrm{mmHg}$ is classified as normal and 1-3 $\mathrm{mmHg}$ as borderline, while more than $3 \mathrm{mmHg}$ indicates potential NCS. ${ }^{[8]}$

Various treatment models such as observation, conservative treatment and surgery are suggested in adult patients. Different concepts and methods are available for the treatment (Table 1). Conservative approach is recommended in children due to 


\section{Table 1}

Treatment strategies are divided into four groups

1) Medical observation

2) Open surgery

- Medial nephropexy (excision of varicose veins)

- Renal vein bypass

- Transposition of the left renal vein

- Autotransplantation of left kidney

- Superior mesenteric artery transposition

- Gonadocaval bypass

3) Stent implantation

- Intravascular stent implantation

- Extravascular stent implantation

4) Intrapelvic chemical cauterization

spontaneous remissions. Medication including medroxy progesteron acetate, goserelin acetate, and antiinflammatory drugs is administered to the patients with isolated pelvic congestion. ${ }^{[9]}$ Severe hematuriarelated anemia is the most common indication for the treatment. Surgery or endovascular treatment is recommended for the patients with tense flank pain. Observation and conservative treatment are also recommended for other patients with NCS. ${ }^{[7]}$

Anterior transposition of the left renal vein is a prominent method for the patients with recurrent hematuria attacks, massive proteinuria, severe flank pain, and posterior NCS accompanied by elevated renal vein pressures. Left renocaval bypass technique is preferred due to low surgery complication risk and maintained lower venous hypertension. ${ }^{[10]}$

Endovascular stent insertion requires long-term anticoagulant prophylaxis. Potentialstent complications include obstruction caused by neointimal hyperplasia development, embolization, and proximal migration of the stent. Although stenting has effective short-term results, long-term results remain unknown due to inadequate data in the literature.

In conclusion, NCS which is a rare disease should be kept in mind in the differential diagnosis among the patients with recurrent hematuria attacks and flank pain. Although endovascular or laparoscopic stenting appear to be an appealing option, open surgical repair still remains reliable.

\section{Declaration of conflicting interests}

The authors declared no conflicts of interest with respect to the authorship and/or publication of this article.

\section{Funding}

The authors received no financial support for the research and/or authorship of this article.

\section{REFERENCES}

1. EL-Sadr AR, Mina E. Anatomical and surgical aspects in the operative management of varicocele. Urol Cutaneous Rev 1950;54:257-62.

2. de Schepper A. "Nutcracker" phenomenon of the renal vein and venous pathology of the left kidney. J Belge Radiol 1972;55:507-11. [Abstract]

3. Urban BA, Ratner LE, Fishman EK. Three-dimensional volume-rendered CT angiography of the renal arteries and veins: normal anatomy, variants, and clinical applications. Radiographics 2001;21:373-86.

4. Barsoum MK, Shepherd RF, Welch TJ. Patient with both Wilkie syndrome and nutcracker syndrome. Vasc Med 2008;13:247-50.

5. Kurklinsky AK, Rooke TW. Nutcracker phenomenon and nutcracker syndrome. Mayo Clin Proc 2010;85:552-9.

6. Santos Arrontes D, Salgado Salinas R, Chiva Robles V, Gómez de Vicente JM, Fernández González I, Costa Subias J, et al. Nutcracker syndrome. Report of a case and review of the literature. Actas Urol Esp 2003;27:726-31. [Abstract]

7. Ekim M, Ozçakar ZB, Fitoz S, Soygür T, Yüksel S, Acar $\mathrm{B}$, et al. The "nutcracker phenomenon" with orthostatic proteinuria: case reports. Clin Nephrol 2006;65:280-3.

8. Dellavedova T, Racca L, Ponzano RM, Minuzzi S, Olmedo JJ, Minuzzi G. Nutcracker syndrome: a case report. Rev Mex Urol 2010;70:51-4.

9. Sezik Ş, Duman Atilla Ö. Makroskobik hematürinin nadir bir nedeni. Tr J Emerg Med 2013;13:7.

10. Liu Y, Sun Y, Jin X. Left renocaval venous bypass with autologous great saphenous vein for nutcracker syndrome. J Vasc Surg 2012;55:1482-4. 